\title{
60
}

\section{Allen Smithee}

When Hollywood film directors found they had lost creative control over their films due to interventions on the part of the film studios, they started to protest by refusing to be credited as directors. Instead, they all used the fictitious name Allen Smithee. Until now, a lot of films, TV episodes and music videos have officially been directed by Alan Smithee - so many that a new pseudonym has been introduced: Thomas Lee. Do not see their films.

(Braddock and Hock, 2001) 